\title{
Effectiveness of the Virtual Learning Environment (VLE) for online teaching, learning, and assessment: Perspectives of Academics and Students of the Royal University of
} Bhutan

\author{
Ugyen Pem ${ }^{1}$, Chenga Dorji ${ }^{2}$, Sangay Tshering ${ }^{3}$, Rinchen Dorji ${ }^{4}$
}

\begin{abstract}
${ }^{1}$ Department of Science Education, Samtse College of Education, Royal University of Bhutan, Bhutan
${ }^{2}$ Department of Mathematics and IT Education, Samtse College of Education, Royal University of Bhutan, Bhutan

${ }^{3}$ Department of Contemplative Counselling and Psychology Education, Samtse College of Education, Royal University of Bhutan, Bhutan. ${ }^{4}$ President, Samtse College of Education, Royal University of Bhutan, Bhutan
\end{abstract}

Received: 25 Jun 2021; Received in revised form: 22 Jul 2021; Accepted: 05 Aug 2021; Available online: 13 Aug 2021 (C2021 The Author(s). Published by Infogain Publication. This is an open access article under the CC BY license (https://creativecommons.org/licenses/by/4.0/).

\begin{abstract}
This study investigated the effectiveness of virtual learning environment features for online Teaching, Learning and Assessment in all colleges of the Royal University of Bhutan. A mixed methods, parallel convergent design was adopted for this study. A total of 155 academics and 650 students participated in online survey questionnaires and 22 academic and 43 students responded to the online semi-structured interview questions. The auto-generated reports of VLE usage of 93 modules across the colleges were analysed to validate the findings on the usage of VLE features by academics from qualitative and quantitative data. The results showed that the academics' overall experience of using VLE for online teaching was positive whereas the majority of the students found it a challenging learning experience. While the academics were found to be competent in using only basic VLE features for online teaching, the students' perceptions of their tutors' competencies in online teaching were diverse ranging from very experienced to a beginner. Both the academics and students found learning through VLE not very effective as assessment and giving feedback online requires previous experience, sound IT knowledge and adequate resources. The results also showed that both academics and students were generally satisfied with the ICT facilities and resources in the colleges. However, students have experienced major constraints such as internet connectivity, financial support, IT facilities, power fluctuation and household chores while learning online from homes. Generally, they have found online learning through VLE as a new enriching opportunity to learn ICT tools, communication skills and social skills for collaborative online learning.
\end{abstract}

Keywords-Online Education, Technology, Virtual Learning Environment (VLE), Teaching Learning and Assessment (TLA), Competence, Effectiveness.

\section{INTRODUCTION}

Information and communication technology (ICT) has become the driving force of globalisation (Idowu et al., 2003) and its influence in education has transformed the entire educational landscape of teaching, learning and assessment (TLA) practices across many education systems worldwide. According to Boylan (2004), technology enabled TLA practices facilitate the use of a variety of multimedia materials that tends to broaden the learning experiences of students and wean them away from the dominant teacher centered instructional practices.

Recognising the importance of harnessing the power of ICT in TLA in tertiary education in Bhutan, the Royal University of Bhutan (RUB) has created a virtual learning 
environment (VLE) in all constituent colleges. RUB's initiative to embrace digital pedagogy in higher education institutions aligns with the national education vision of emphasising on the pervasive use of ICT in education to make the learners "nationally rooted and globally competent citizens through equitable and pervasive use of merging and relevant technology" (Ministry of Education, 2019, p.xi). Further if Bhutan is to realise her vision of building an ICT-enabled, knowledge-based society as a foundation for Gross National Happiness (GNH) as enshrined in the eGov Master Plan developed in 2012 (Ministry of Education, 2019), RUB as the key higher education institution (HEI) in the country will need to lead and model good practices of integrating ICT as a primary TLA tools.

However, despite the provision of VLE to encourage the use of ICT in teaching and learning in the colleges of RUB for over a decade, the optimal utilisation of different features of VLE to teach courses did not happen seriously until the beginning of 2020 when the COVID-19 pandemic led to the closure of schools and institutions creating the need to use VLE for online teaching an inevitable choice. The need for a sudden transition from face-to-face teaching to full mode online teaching possibly could have resulted in some kind of panic, anxiety and hesitation amongst the academics and not many have been active in using VLE as a platform for teaching courses and not all academics across the colleges of RUB have the same level of ICT knowledge and skills. Although the majority of RUB academics do possess basic ICT knowledge and skills, many have used VLE to share the Semester Teaching Term Plans and upload reading materials with very few academics who have a good knowledge of the use of different features of VLE for TLA. The VLE features such as students' classroom attendance, lessons, discussion forums, assignments, feedback to students' work, H5P interactive content, quizzes, workshop, blogs, and a variety of other plug-in features have been left underutilized hitherto.

For the majority of the academics in the colleges of RUB, there are indications that the ill-preparedness and inadequate knowledge of using VLE for online teaching has affected the delivery of an effective online teaching that is engaging, interactive, interesting and exciting, thus affecting the quality of online teaching and learning. There are instances of students complaining of online teaching being less interactive, devoid of human touch and presence to make learning more exciting and purposeful.

Therefore, this study was conducted to explore and investigate the perspectives of academics and students of the Royal University of Bhutan regarding the effectiveness of the VLE for online TLA.

The expected outcomes are:

- determine the overall experiences, usage, and competency of RUB academics and students using VLE features;

- test whether gender, age, teaching experience, and education qualification of college academics influence on the use of VLE features for online TLA; and

- $\quad$ analyse the benefits and challenges of using VLE for online TLA.

\section{LITERATURE REVIEW}

\section{Online education}

Online learning and teaching is generally understood as courses that are delivered completely online using an online learning platform. Ever since the introduction of online teaching by the University of Illinois in 1960 (Tom, 2017), it has gradually gained momentum in higher education especially in developed countries. Such transition in teaching-learning culture was mainly driven by the advancement of the internet and technology considering its positive influence to facilitate effective teaching and learning processes. By reviewing 151 articles on online teaching, Singh and Thurman (2019, p.302) defined online education as:

Online education is defined as education being delivered in an online environment through the use of the internet for teaching and learning. This includes online learning on the part of the students that is not dependent on their physical or virtual co-location. The teaching content is delivered online and the instructors develop teaching modules that enhance learning and interactivity in the synchronous or asynchronous environment.

Many researchers tried to differentiate between synchronous and asynchronous learning environments. According to Bourne et al. (2019,p.30), "Synchronous online systems can permit nearly the same level of interaction as in typical classrooms". The students are required to attend live lectures or participate in virtual meetings at specific times in a synchronous learning environment. In this case students' interactions with lecturers and friends, and there is a possibility of instant feedback on their progress of learning (Adzima,2020;Dhawan,2020). In an asynchronous learning environment, students are not required to attend 
live lectures or participate in virtual meetings at specific times and do not get instant feedback on their progress.

According to Appanna (2008), online education is multifaceted in increasing access to education, improving the quality of learning, reducing costs, preparing students better for a knowledge-based society, responding to market demand and installing a sense of "lifelong" collaborative learning opportunity across the globe. Moreover, to effectively teach 21 st century learners who are strongly connected to digital technology, digital communication and notions of flexible approaches to learning, new ways of learning and teaching are of paramount importance (Wood, 2019). Most universities and higher education institutions make concerted efforts to develop online course capability to cater to the fast-growing cyber education market (Love \& Fry, 2006). Similarly, Bhutan also has recognised the immense potential of technology in education in building an 'ICT-enabled, knowledge-based society as a foundation for Gross National Happiness" (Ministry of Education, 2014). iSherig-2, Bhutan's Education ICT Master Plan 2019-2023 lays out an ambitious plan to be implemented across the entire education system including the two colleges of education (Ministry of Education, 2019).

\section{Meaning of Virtual Learning Platform (VLE)}

Among many, Moodle is one such online learning platform for online teaching in higher education. Moodle refers to an acronym for Modular Object Oriented Developmental Learning Environment, which is also used interchangeably with other terms such as Learning management System (LMS) or Virtual Learning Environment (VLE) (Moodle, 2020). It is widely used by universities worldwide, communities, schools, and teachers to conduct courses fully online or to complement face-to-face (F2F) teaching and learning (Lopes, n.d). Although in Bhutan, the colleges of RUB have been using VLE for teaching and learning since 2011 (Kinley et at., 2013), the use of VLE as an online teaching and learning platform at Samtse College of Education (SCE) dates back to as early as 2004 in offering the distance teacher education programmes to in-service teachers (Jamtsho\& Bullen, 2007).

\section{Effectiveness of Virtual Learning Environment (VLE)}

VLE as an online teaching and learning platform is found to be an enabler of content delivery as it is not bound to a specific time and place but can be accessed anytime and anywhere (Molotsi, 2020). A study on "Evaluating students experiences using VLE: Satisfaction and preference in Middlesex University, England"revealed that students' preferred lecture capture and key concepts videos because of their benefits on learning, whereas lecture capture with PowerPoint slides and audio only were not preferred considering its lesser benefits (Hamutoglu et al., 2019). Lyndon and Hale (2014) highlighted the importance of using VLE for students' engagement with the potential to enhance higher learning skills through the use of interactive online activities such as discussion forums. The study recommended to empower the university teachers to use other VLE interactive tools to promote participation and engagement among students (Molotsi, 2020). However, Hamutoglu et al. (2019) pointed out that students are not so enthusiastic in using discussion forums, chatrooms, access to blogs, audio/video conferencing facilities and wikis. Overall, a study by Maltby and Mackie (2009) stated that VLE can help or hinder student engagement and performance and that they should be adapted to the different types of learners. Further, Nguyen (2015) found that online teaching resulted in improved test scores, student engagement, improved perception of learning, higher engagement with learning materials, stronger sense of community and reduction in failure. Online education programs provide opportunities to those students who are disadvantaged by geography, time and financial support (Crawford-Ferre\&Weist , 2012). Positive attitude is exhibited on the use of VLE regardless of gender. On the other hand, young and experienced users of e-learning platforms tend to be difficult to satisfy with regards to the use of VLE (Chua \&Montalbo, 2014).

\section{Competency of academics and students in using VLE as an online teaching and learning platform}

The colleges under RUB shifted to online teaching during COVID-19 pandemic outbreak. The academics realigned their teaching approaches and technological knowledge and skills in designing, managing and delivering the online courses. Mazlanet. al. (2021,p.719) found that many educators in tertiary institutions faced challenges in online remote teaching and learning. Several studies have emphasized on the key competencies that academics need to develop and demonstrate in designing, managing and delivering effective online courses. They are:

\section{(i) Student-centred instruction}

The VLE has features which enable academics to create student-centred learning activities. The student-centred instruction helps students to achieve higher order thinking skills and improve students' participation in online TLA. Incorporating flexibility within learning environments allows discussions to evolve when deconstructing content and a number of ways to explore the subject matter to develop while also fostering the sense of community and building relationships (Gillett-Swan,2017,p.28)

(ii) Collaborative learning 
The academics and students use synchronous tools (Video and audio conferencing) and asynchronous tools (WhatsApp, WeChat, Facebook, and VLE) to deliver, manage and support students during online teaching. Social interactions in the online discussion forums improve students' participation in collaborative learning (Lyndon \& Hale, 2014). According to a study carried out by Mazlan et al.(2021,p.719), "During this pandemic outbreak, educators face difficulties in motivating students to participate and stay attentive during online learning." Further Coman et al.(2020,p.14) found, "Students easily get distracted and lose focus due to the fact that teachers do not have well implemented strategies in order to keep them focused, but also because of their lack of experience with this type of learning".

(iii) Feedback skills

Online learners get motivated and interested in online lessons if timely feedback (written or audio) are provided on their online progress of study. According to Cole et al., 2017 cited in Mazlan et al. (2021) found that prompt instructors' feedback and frequent presence enhance students' motivation to participate in online teaching and learning. However, educators face difficulties in motivating students to participate and stay attentive during online learning (Mazlan et. al., 2021,p.719).

\section{(iv)Management of the VLE}

The 21 st century world is becoming increasingly digitised which is another reason why it is important for academics to be more aware of the specifics of their cohorts and learners and find ways to engage with and support isolated learners (Gillett-Swan, 2017, p.27).It is also important for academics to update and manage the learning resources on VLE which are useful and relevant for the learners.

(v) Content development for online delivery

Online education creates anxiety amongst academics and students. According to Gold (2001), teachers who have the actual experience of online learning before or experienced in developing content and teaching online are expected to be competent teachers. Otherwise, they will simply map traditional practices onto the new medium with little transformation necessary in the teaching process. Similar study by Kebritchi et al. (2017, p.11) said, "Content cannot simply be copied from a face-to-face to an online setting". The educators must adapt to new and creative strategies to engage students during online remote teaching and learning (Paudel, 2021; Kebritchi et al., 2017). Further, Mazlan et al. (2021) said, "Tertiary institutions explore suitable strategies to ensure students are able to learn effectively".

\section{(vi) Online facilitation skill}

Facilitating an online class is very different from a face-toface class. It is different because the location of the teacher is physically separate from the student, and information can be stored and transmitted across time and space (Gold,2001).Some teachers may fear exhi-biting a perceived technological weakness when using the VLE platform in front of students who might be more digitally savvy(Herrera, 2017, p.483)

(vii) Education technology skills

Students' motivation level decreases because of technical problems. Several studies have revealed the importance of technology skills required by the teachers and students to implement online education effectively (Mazlan et al., 2021; Paudel, 2021;Coman et al.,2020). The difficulties and problems associated with modern technology range from downloading errors, issues with installation, login problems, problems with audio and video, and so on (Dhawan,2020,p.8).

\section{Challenges}

The challenges faced by the academics and students during the onlineTLA process are discussed below.

(i) Lack of technological support to students is suspected of hindering students' participation in online classes.

Technical problems are one of the most prominent problems that hinders the students' participation and motivation in online classes.

According to Coman et al. (2020,p.17), they suggested:

When students encounter technical difficulties, teachers should come up with solutions so that students could have access to the information provided during courses (recording and posting the course on the platform, offering supplementary materials), and if solutions cannot be found, the least teachers could do is to be understanding and to not sanction students due to this type of issues.

(ii) Incompetent use of VLE features by academics and students

Academics play a vital role in improving students' participation and interactions on the VLE platform. Coman et al. (2020,p.16) found that the students' lack critical thinking skills, lack of ability to debate and express their opinion are now becoming prominent in the higher education system in the process of online learning beside other factors like the physical, social, financial and emotional support at home. Stodel et al.(2006) found that academics need to spend more time teaching learners how to communicate, collaborate, and build community 
effectively online if we want to enhance social presence. Students felt that the communication was more formal online than it would have been in F2F, which appeared to diminish the sense of presence. Without adequate knowledge of using VLE features, it would be difficult for academics and students to participate and interact effectively during online teaching and learning.

\section{(iii) Lack of online students disciplines}

The students are responsible for their own learning during online education. Those who are not self-disciplined, this mode of learning becomes a big challenge because everything depends on them (purely self-tuition) as against face-to-face learning where colleagues and instructors serve as helpers and encouragers in the learning process(Koi-Akrofi et al., 2020,p.34). The students who are not able to do independent work and not able to copeup with online education, they resort to malpractices and play truancy during online education and tend to plagiarize the work of others (Adzima,2020).

(iv)High cost associated with online development and delivery

In developed countries like the USA, UK and Australia, online education is offered for mass enrollments into undergraduate and postgraduate courses with affordable tuition fees compared with full-time courses. Nguyen (2015,p.310) reports, "the rising cost of postsecondary education and the importance of a postsecondary degree are well documented in the literature". The universities have invested a lot of resources for the development of online resources and upgrading the knowledge and skills of online teachers, developers and trainers. Without these knowledge and skills, educators will find it difficult to prepare materials for online teaching and learning (Azlan et al., 2020). The technology infrastructures and facilities in the institutions are the most essential requirements for the academics and students for delivering quality online courses. Limited and low internet connections are the main reasons that will hinder effective online teaching and learning for educators and students (Mazlan et al.,2021)

(v) Time management

One of the challenges faced by the academics and students is time management during online teaching. A sudden shift from face-to-face to online teaching have resulted in issues related to online learners, instructors, and content development(Paudel,2021; Kebritchi et al., 2017:Dhawan,2020). Moreover, according to Parkes et al., 2014 as cited in Dhawan (2020) there is a low-level preparedness among the students concerning the usage of Learning Management Systems. It takes time for academics to prepare lessons for online TLA and for students to adjust with the online pedagogy.

\section{(vi) Coping with personal stress}

There are numerous personal stresses experienced by the academics and students during online TLA. According to Chandra (2020), those students who are not able to live up to parents and teachers' expectations. And all these lead to experiencing feelings of stress and burnout among students. The students lose interest in online TLA if there is lack of individual support from their tutors. Students want two-way interaction which sometimes gets difficult to implement (Dhawan, 2020, p.8) Students in the rural places are not able to enjoy online TLA because they have lots of responsibilities beside problems with internet speed. However, Paudel (2021) found that many adult learners may enjoy the flexibility when they have to balance work, study, and family responsibilities. On the other hand, teachers are finding it more time consuming and difficult to set up assignments, quizzes and exam papers that are not easy to attempt(Ahmed \&Ikram Khan, 2020, p.11). Moreover, some academics and students are not competent at using video streaming platforms such as Zoom, Google Meet, YouTube,Skype, and others for virtual meetings. Majority of academics consult other experienced colleagues to transform their teaching to online (Hjelsvold et al.,2020).

(vii) English as an instructional language especially for those students or learners where English is not a native language.

Communication plays an important role in achieving the students' learning outcomes. During online interactions, only students who have good communication skills can clarify their doubts and participate actively in online discussion. Those students who lack communication skills (writing and speaking) enjoy meeting fellow students and ask in-person questions which can make their learning easier (Koi-Akrofi et al.,2020).

\section{METHODOLOGY}

The mixed methods approach, specifically convergent parallel design, was employed to carry out the research. Given the aim, scale and appropriateness of the research design, three research instruments; survey questionnaires, semi-structured interview questions and document analysis (auto-generated reports of VLE usage) were used as tools to collect the required data. Creswell (2014,p.540) describes, "A convergent parallel mixed methods design will involve simultaneously collecting both quantitative and qualitative data, merging the data and using the result to understand the problem investigated". All the instruments were repeatedly improved after receiving feedback from experts and ultimately ran reliability tests using SPSS. With the confidence of all research 
instruments, they were sent to all the colleges via group/individual emails along with all necessary documents. The information sheet and consent form were sent to individual participants via email and upon their consent to participate, and the Google Form links were shared to collect written responses on 13 semi-structured interview questions.

A total, 650 students $(49.2 \%$ female and $50.8 \%$ male $)$ and 155 academics (30.3\% female and $69.7 \%$ male) have responded to the survey questionnaires and 43 students
(53.5\% female and $46.5 \%$ male) and 22 academics (36.4\% female and $63.6 \%$ male) participated in answering online semi-structured interview questions from RUB colleges as shown in Figure 1. The composite of CA by age, teaching qualifications, and teaching experiences are shown in Table 1, Table 2, and Table 3 respectively. Similarly, the composite of CS by age is shown in Table 4. Likewise, auto-generated reports of VLE usage of 93 modules from nine colleges were collected and analysed as illustrated in Figure 2.

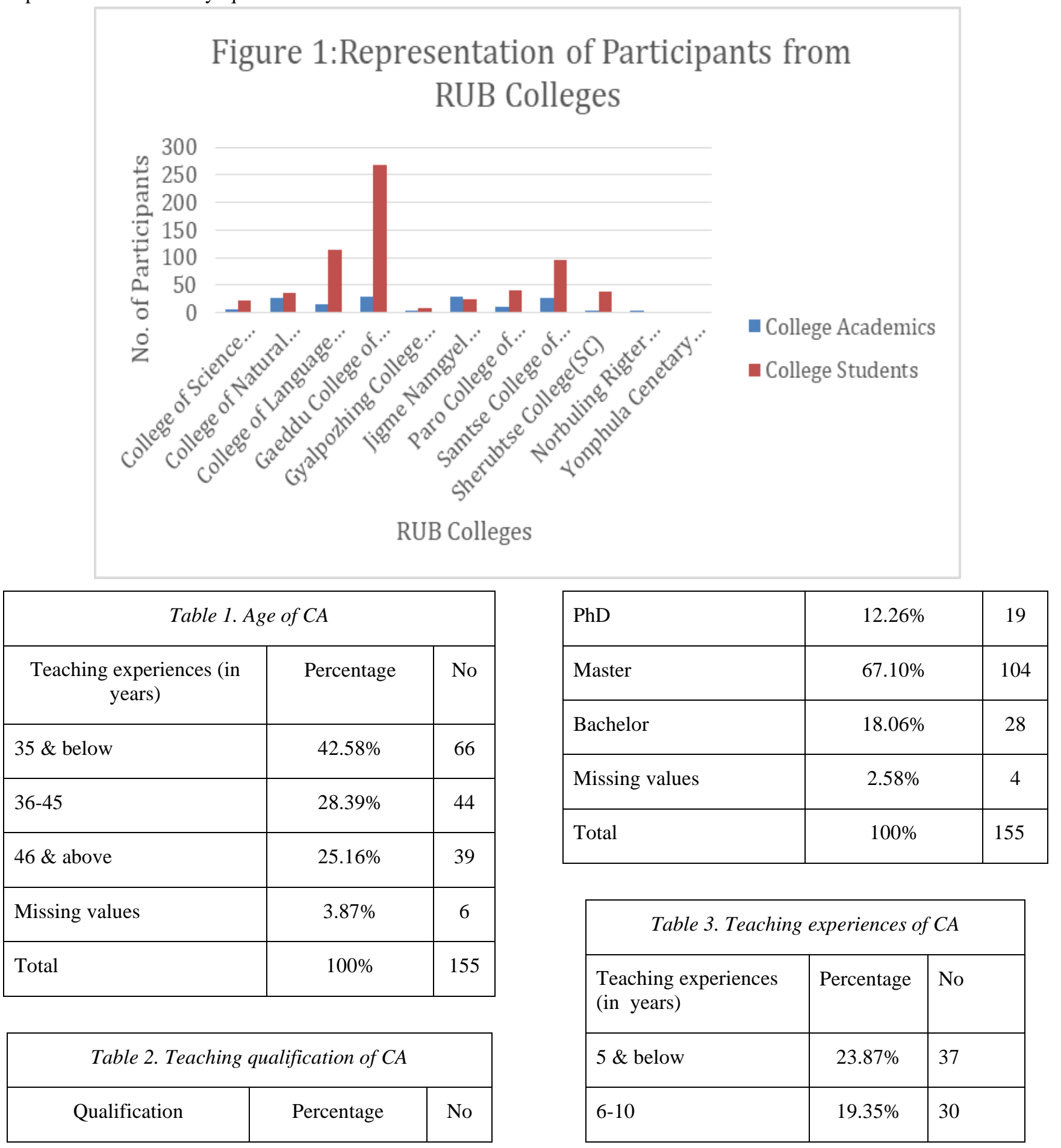




\begin{tabular}{|l|l|l|}
\hline $11-15$ & $20.65 \%$ & 32 \\
\hline $16-20$ & $14.19 \%$ & 22 \\
\hline 21 \&above & $18.71 \%$ & 29 \\
\hline Missing values & $3.23 \%$ & 5 \\
\hline Total & $100 \%$ & 155 \\
\hline
\end{tabular}

\begin{tabular}{|l|c|c|}
\hline \multicolumn{3}{|c|}{ Table 4. Age of CS } \\
\hline $\begin{array}{c}\text { Teaching experiences (in } \\
\text { years) }\end{array}$ & Percentage & No \\
\hline 20 \& below & $22.62 \%$ & 147 \\
\hline $21 \&$ above & $77.38 \%$ & 503 \\
\hline Total & $100 \%$ & 650 \\
\hline
\end{tabular}

The Survey data were entered into the Statistical Package for Social Sciences (SPSS 25). Reverse coding for some scale items, data screening, missing value analysis and recoding for some categorical items across the survey questionnaires were carried out. Descriptive statistics such as frequencies, crosstabs and exploratory analysis were used to describe and summarise the demographic characteristics.

Principal component analysis (PCA) was run on 49 scale items of $\mathrm{CA}$ produced seven valid components which accounted for $70.79 \%$ of the variance in the items. These seven components demonstrated acceptable reliability as shown in Table 5.

\begin{tabular}{|c|c|c|}
\hline \multicolumn{3}{|c|}{ Table 5: Reliability Statistics of CA } \\
\hline $\begin{array}{c}\text { Cronbach's } \\
\text { Alpha }\end{array}$ & $\begin{array}{c}\text { Cronbach's Alpha Based on } \\
\text { Standardized Items }\end{array}$ & $\begin{array}{c}\mathrm{N} \text { of } \\
\text { Items }\end{array}$ \\
\hline .525 & .509 & 7 \\
\hline
\end{tabular}

Similarly, PCA on 50 scale items of CS produced six valid components which accounted for $69.87 \%$ of the variance in the items. These six components demonstrated acceptable reliability as shown in Table 6.

\begin{tabular}{|c|c|c|}
\hline \multicolumn{3}{|c|}{ Table 6: Reliability Statistics of CS } \\
\hline $\begin{array}{c}\text { Cronbach' } \\
\text { s Alpha }\end{array}$ & $\begin{array}{c}\text { Cronbach's Alpha } \\
\text { Based on Standardized } \\
\text { Items }\end{array}$ & $\begin{array}{c}\text { N of } \\
\text { Items }\end{array}$ \\
\hline .688 & .703 & 6 \\
\hline
\end{tabular}

The Mann-Whitney U test was conducted to determine the influence of gender of CA on effectiveness of VLE for TLA $(\alpha=.05)$. Further, a Kruskal-Wallis test was conducted to determine the influence of age, teaching experience and educational qualification of $\mathrm{CA}$ on the effectiveness of VLE for TLA $(\alpha=.05)$.

Raw data gathered from semi-structured interviews were transcribed, coded and categorised into various themes for the interpretation of the qualitative components of the data. The auto-generated reports on the usage of VLE features by the academics were also analysed for interpretation and confirmation. For ethical reasons, the CA respondents of the semi-structured interviews are referred to as L1, L2, L3... L22 and the CS respondents as S1, S2, S3 ... S43.

\section{RESULTS AND DISCUSSIONS}

This section presents the results and discussion of the five themes generated by coalescing the analysis of quantitative and qualitative data. The discussion on each theme is supported by relevant literature, verbatim quotes from the interview and open-ended data.

\section{Tutors' and Students' Overall Experiences of using} VLE

In any given phenomenon of life, the basis of human experience is detrimental to individual differences and numerous factors.

The semi-structured interview data on the experience of using VLE of both academics and students can be largely categorised as 'positive' and 'challenging' experiences. Out of $22 \mathrm{CA}$ respondents, 4 labelled their experience as 'excellent', 2 as 'very good', 8 as 'good', 2 as 'interesting', 4 as 'interactive', 4 as 'user friendly' and 4 as 'helpful and useful'. For instance, L10 and L12 highlight experiences as 'convenient to upload resources, assign work, make students discuss and can be used for assessment. It has reminders, can be used to communicate with individual students and other face to face online can be done'. The academics who have rich experience in using the features of VLE are able to deliver online lessons effectively. L13 said, 'A few features that I used were very useful to build interaction with students, promote discussion between and 
among students, upload useful materials and even check their progress from time to time'. In contrast, four academics contended as 'challenging' experiences of using VLE for online teaching (L9, L4, L8, and L13). Despite their differences in expression, the majority of academics have found online teaching to be a 'positive' experience. However, network fluctuation, not being able to use all VLE features, and vague students' participation were reflected as 'challenging' experiences of online teaching (L9, L4, L8, and L13).

Similarly, out of 43 student respondents, 11 of them expressed as 'effective', 12 of them as 'new learning experiences' and 14 of them as 'challenging' experiences. S31 highlighted, 'effective learning via online teaching on VLE as we can clear our doubts by referring again and again'. Further S12 expressed it as 'new experience and I enjoyed learning online. It was very convenient and effective'. Conversely, 32.5\% $(\mathrm{N}=14)$ of the students expressed numerous issues related to online learning. Many hitches discouraged them from learning effectively. S34 expressed, 'Learning online is really hectic. As a middle class working family, managing the time is difficult. Moreover we have to do household chores and studies hand in hand'. Similarly, S42 said 'It was challenging and difficult to learn through online sessions because of poor net connections, unclear teachings and sometimes diverted to using other apps'. Ahmed and Ikram Khan (2020, p.12) found the following:

The networking issues, most probably due to the exponential rise in network usage during COVID19. According to one of the student respondents, "Google classroom and WhatsApp recorded lectures were much better. In zoom, there are always network issues; you can't hear the teacher properly or the teacher can't hear you.

In the same context, S6 experienced that it was difficult to concentrate and catch up during online sessions if the network fluctuated. Likewise, as online learning is totally dependent on the internet and computers, accessibility, system errors and other interruptions may easily distract online learners and lose focus and miss deadlines (Sadeghi, 2019).Owing to numerous issues, it is evident that the majority of students have described online learning as a 'challenging experience'.

Overall, the qualitative data reveals contradicting findings that the majority of academics' experience is 'positive' whereas students' found online learning a 'challenging' experience. Olsen (2007) suggests that tutors can meaningfully engage students by integrating multimedia, chats, simulators, images, virtual classrooms, audio and video. Thus, one's experience of online teaching and learning is affected by numerous factors.

\section{Tutor's teaching and competencies of using VLE}

The descriptive analysis of the composite item on this theme of CA has mean score and standard deviation $(M=$ 4.52; $S D=0.919)$, indicating the higher side of the six point Likert scale without much variability. This shows that they are competent to use a variety of VLE features for effective online teaching. The tutors' claim has been further affirmed by descriptive analysis of CS with the mean score and standard deviation $(M=4.19 ; S D=1.173)$ with less variability. Further, Mann-Whitney U test was conducted to see the influence of gender of CA on the use of VLE features for online teaching. The male CA has a (Mean Rank =77.20) which was not statistically significant different $(z=-1.52, p=.128)$ from female CA on the same variable (Mean Rank=65.14), thus concluding that there is no influence of gender on use of VLE features for online teaching. Furthermore, a KruskalWallis test revealed no statistically significant difference in CA across the three age groups, $\chi 2(D F=2, N=149)=$ $1.372, p>.05$, age group were lower in the $46 \&$ above years $(M d=4.40)$ in comparisons to the $36-45$ age group $(M d=4.60)$ and $35 \&$ below group $(M d=4.80)$. Thus, concludes that age has no influence on use of VLE features for teaching. Similarly, Kruskal-Wallis test also revealed that teaching experience and educational qualification have no influence on use of VLE features for online teaching.

The qualitative data analysis of the CS revealed varied perceptions of their tutors' competency level ranging from 'experienced' to 'beginners' of using VLE for online teaching. Out of $43 \mathrm{CS}$ respondents, a total of 22 expressed their tutors as 'experienced', while 7 as 'potential' and the rest of them as 'beginners' of online teaching using the VLE platform.

In terms of perception over experiences, around $23 \%$ of CS respondents expressed that tutors are having adequate knowledge in making online teaching effective and joyful through use of varieties of VLE features. For instance, S12 said 'some of the tutors are very knowledgeable in terms of online features. They make the session realistic and fun through different features like breaking into groups, getting feedback, conducting quiz and zoom'. The student respondents also described the tutors as skillful in online teaching using the VLE platform (S8, S9, S17, S29, and S30). Likewise, students expressed that they have observed tutors giving their best to make online teaching interactive and engaging (S2, S16, and S19). Contrarily, around $16 \%$ of CS respondents articulated the 
need of tutors to learn the VLE features as they were not able to make online learning interactive and meaningfully engaging. Moreover, a few CS respondents described their tutors as just beginners of online teaching. For instance, S22 stated 'I feel like tutors are more or less like students in terms of knowledge and skills of online teaching'.

Further S13 also articulated:

In the 21 st century, the teaching is entirely different compared to the past. Therefore, I think upskilling and reskilling ICT for teachers seems crucial since most academics lack the ideas about IT especially while teaching online. Thus, teachers need to reskill and upskill the knowledge and skills about modern technology/other VLE platforms.

Yusuf and Yusuf (2009) highlights that the use of ICT as a tool for TLA in education empower teacher's teaching and promote the acquisition of knowledge and skills essential to 21 st century learners.

As per the analysis of auto-generated reports given below in Figure 2, it shows that maximum features used are 'file', 'Zoom', 'assignment', 'forum', 'folder' and 'URLs' which are basic VLE features.

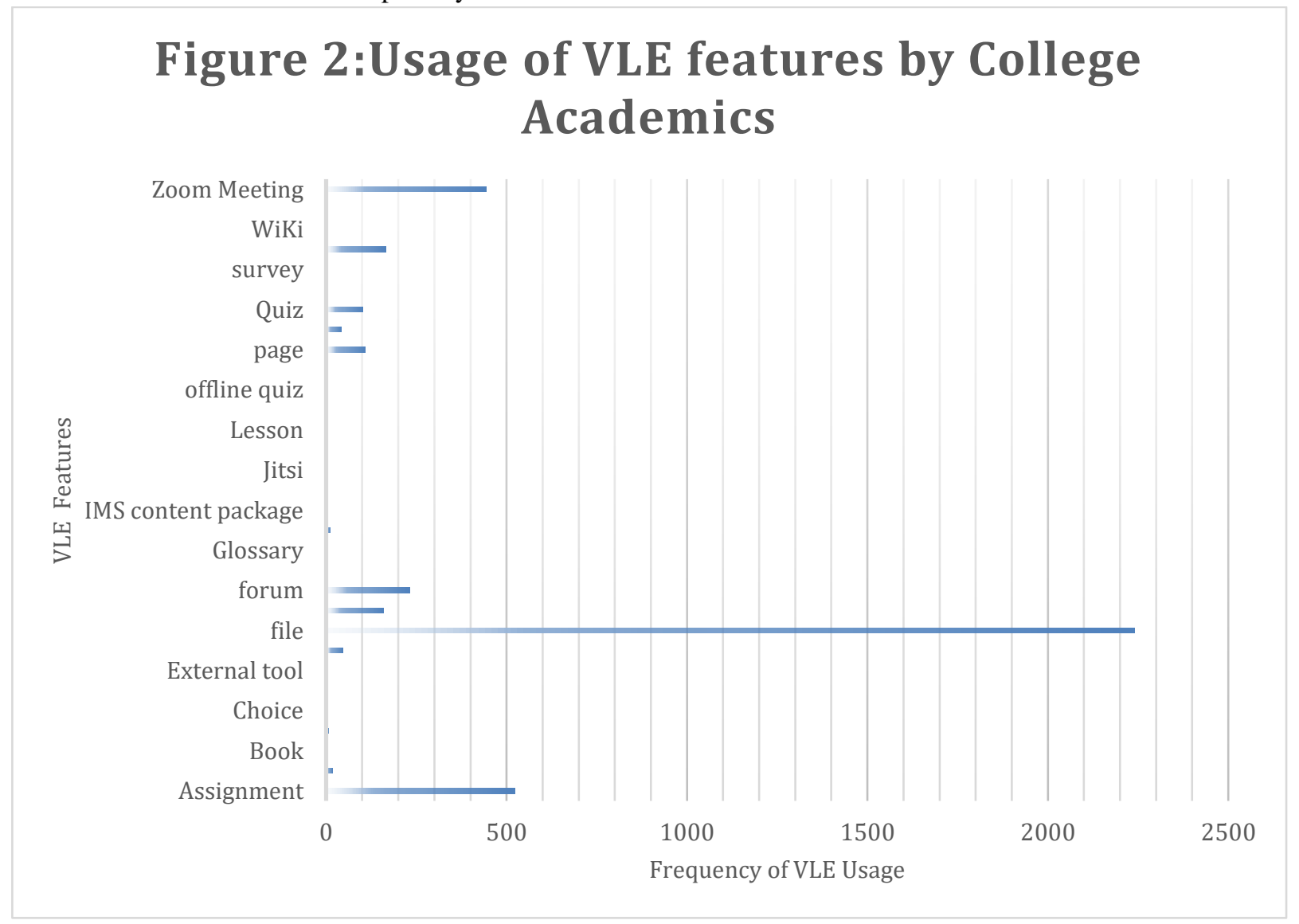

Although quantitative data analysis indicated that academics are competent in using VLE for effective online teaching yet qualitative data analysis found varied perceptions of tutors' competencies ranging from 'experienced' to 'beginner' but auto-generated reports revealed basic usage of VLE features. Such level of usage by the academics can be attributed to numerous professional development courses at individual college level and also an orientation of VLE provided to newly recruited academics by the Centre of University Learning and Teaching (CULT) programme. As Gold (2001,p.35) states:
In order to make online teaching effective, engaging and interactive, teachers must have the actual experience of online learning before they can be expected to be online teachers; otherwise, they simply map traditional practices onto the new medium with little transformation necessary in the teaching process.

In the same line Kebritchi et al.(2017)found that academics are not competent to design materials for online teaching.

However, RUB colleges resorted to online teaching for the first time during the confirmation of the first corona case 
in Bhutan (Chezom\& Dem, 2020).These instances enabled the researchers to broadly conclude that CA possesses somewhat competent in using VLE features for online teaching. Around $32 \% \mathrm{CA}$ respondents expressed that VLE is effective to complement the actual face-to-face teaching. For instance, L4 highlighted as 'I think such a platform can be very useful whenever face to face teaching becomes impossible due to unavoidable and unforeseen circumstances'. Alves et al. (2017) also point out that VLE is being used by universities, schools and companies, not only to incorporate web technology into their courses, but also to complement their traditional face-to-face courses.

\section{Students' Learning and Competencies of using VLE}

The descriptive analysis of the composite item "Students competency of using VLE" of CS has mean score and standard deviation $(M=3.31 ; S D=1.183)$, indicating a somewhat lower side of the six point Likert scale with some variability. This shows that they are somewhat incompetent to use VLE features for online learning. Similarly, the descriptive analysis of the composite item "Students engagement in learning" of CS has mean score and standard deviation $(M=3.23 ; S D=1.196)$, indicating a somewhat lower side of the six point Likert scale without much variability. This also shows that online learning through VLE features is somewhat not effective to engage them in learning. The students' claims have been further affirmed by descriptive analysis of the CA with mean score and standard deviation $(M=3.04 ; S D=.969)$ with less variability.

As per the qualitative data analysis, $30 \%$ of CS respondents have claimed to be somewhat competent and another $30 \%$ of CS respondents incompetent to use VLE for online learning. However, a few CS respondents claimed to be highly competent. In terms of highly competent, $19 \%$ of CS respondents expressed that online learning enables flexible learning, participation and clarification of doubts. For instance, S18 stated 'I am very comfortable learning through online because we can take the classes from anywhere and anytime'. While $30 \%$ of CS respondents described that online learning facilitates accessibility of resources, exploratory learning and resulting in comprehension of contents delivered by the tutors. For instance, S17 said:

I feel I am competent enough to learn via online as I have ICT knowledge, laptop and mobile phone which are needed to participate. Moreover, we are already taught with the use of VLE.

The other CS respondents conveyed that online learning has many barriers such as internet connectivity, data consumption and other issues (S7, S10, and S32). A study by Comen(2021) found that the students faced technical problems due to poor internet connections, signal loss, lack of adequate digital devices, especially for students living in rural areas or students from families with low incomes.

Similarly, unlike face-to-face, online learning does not engage meaningfully especially in carrying out practical works (S8, S11, S14, and S39). Moreover, online learning does not accommodate the needs of diverse learners as they find it very difficult to understand the contents delivered by the tutors (S6, S24, and S42).

Furthermore, the qualitative analysis of the CS respondents generally conveyed fewer advantages and voiced out more issues about students' learning through VLE. It was observed that online learning promotes more participation of those learners who were normally silent during face-toface classroom (L5 \& L19). It also facilitates collaborative learning among students using VLE discussion forums (L2 \& L16). On the other hand, some academics have expressed that online learning should complement face-toface classroom (L4, L8, L10 \& L20) as it is difficult for the students to learn and does not promote critical thinking skills (L1 \& L6). Stodel et al.(2006) suggested that academics need to spend more time teaching learners how to communicate, collaborate, and build community effectively online if we want to enhance social presence.

The findings from the above data suggest that students were not adequately engaged for meaningful learning owing to various reasons. One of the reasons could be, academics were not trained enough to use advanced VLE interactive tools to promote participation and engagement among students (Molotsi, 2020). Since only basic VLE features were used by academics such as discussion forums, chat rooms and assignment, it would have been difficult to satisfy the needs and fully engage the young digital natives (Chua \& Montalbo, 2014:Hamutoglu et al. 2019).

\section{Online assessment for students' learning}

The descriptive analysis of the composite item "VLE features used for assessing student's learning outcome" of CA has mean score and standard deviation $(M=2.91$; $S D=0.927$ ), indicating a somewhat lower side of the six point Likert scale without much variability. This shows that they are somewhat incompetent to use VLE features such as H5P, blogs, workshops and WiKi for assessing student's learning outcomes. However, based on qualitative data analysis of CA and CS, maximum VLE features used for assessment of students' learning are quiz, forum and assignment. Further, Mann-Whitney U test was conducted to see the influence of gender of CA on the use of VLE features for assessment. The male CA has a (Mean 
Rank=75.30) which was not statistically significant different $(\mathrm{z}=-.619, p=.536)$ than female CA on the same variable (Mean Rank $=70.40$ ), thus concluding that there is no influence of gender on use of VLE features for assessment. Furthermore, a Kruskal-Wallis test revealed no statistically significant difference in CA across the three age groups, $\chi 2(D F=2, N=149)=2.444, p>.05$ age group were lower in the $36-45$ age group $(M d=2.75)$ in comparisons to the $35 \&$ below age group $(M d=3.00)$ and $46 \&$ above age group $(M d=3.00)$. Thus concludes that age has no influence on the use of VLE features for assessment. Similarly, Kruskal-Wallis test also revealed that teaching experience and educational qualification have no influence on the use of VLE features for assessment.

The descriptive analysis of the composite item "online assessment and giving feedback" of CA has mean score and standard deviation $(M=4.54 ; S D=.775)$, indicating higher side of the six point Likert scale without much variability. This shows that they gave constructive and timely feedback to the students' assignment during online assignment. The tutor's claim has been further affirmed by the descriptive analysis of the CS with the mean score and standard deviation $(M=3.82 ; \quad S D=1.153)$ with less variability which is ofcourse lower score than CA but somewhat higher side of the six point Likert scale. Further, Mann-Whitney U test was conducted to see the influence of gender of $\mathrm{CA}$ in providing constructive and timely feedback to the students' assignment. The male CA has a (Mean Rank=72.89) which was not statistically significant different $(z=-.528, p=.597)$ than female CA on the same variable (Mean Rank=77.06). This concludes that there is no influence of gender in providing constructive and timely feedback to the students' assignment. Furthermore, a Kruskal-Wallis test revealed not a statistically significant difference in CA across the three age groups, $\chi 2(D F=2$, $N=149)=3.247, \mathrm{p}>.05$ age group were lower in the $35 \&$ below age group $(M d=4.50)$ in comparisons to the 36-45 age group $(M d=4.63)$ and $46 \&$ above age group $(M d=4.75)$. Thus concludes that age has no influence in providing constructive and timely feedback to the students' assignment. Similarly, Kruskal-Wallis test also revealed that teaching experience and educational qualification have no influence in providing constructive and timely feedback to the students' assignment.

From the qualitative data analysis, CA have generally perceived online assessment and giving feedback as challenging tasks. The lack of IT knowledge and experiences of online grading were voiced out as main reasons. Several studies have highlighted computer literacy as a fundamental aspect to become a proficient online course developer and instructor ( Coman et
al.,2020;Li \& Lee, 2016;Mazlan et.al, 2021; Paudel, 2021 ; Yusuf \& Yusuf, 2009).

On the other hand, some CAs have perceived online assessment as convenient (L3,L8,L10, and L17) and effective(L6,L7,L18, and L19). They have found it convenient as it is transparent and easy to provide feedback. As such, it was effective as it is easy to assign assignments and provide feedback particularly using online quizzes. L19 states, 'In the VLE platform, it is easy for students to submit assignments and teachers can evaluate and give feedback through the platform'.

The qualitative data analysis of the CS on the views of online assessment and giving feedback by the tutors have diverse opinions. Around $19 \%$ of CS respondents found it effective as their assignments were well graded with detailed feedback, marks were transparent, saved resources and time which eventually enabled them to score higher grades. Moreover, it was described as fair enough since the assignment rubrics were shared in advance in VLE, allowing users to submit the draft version which were graded accordingly by the tutors (S3, S4, S7, S17 and S21). On the other hand, around $14 \%$ of CS have been perceived as not effective particularly in carrying out laboratory work, online presentation and group assignments. For instance S11 stated, 'It was not effective as we had hard time learning the practical portion'. However, there are some CS who found online assessment to be the same as that of face-to-face since they were into such practices before (S1, S5, S8, S18 and S30).

The descriptive analysis of the composite item "Academic integrity" of CA has mean score and standard deviation $(M=3.64 ; S D=.593)$, indicating somewhat higher of the six point Likert scale without much variability. This shows they somewhat believe online learning encourages plagiarism and dishonesty in writing assignments and cheating online tests and examinations. Adzima (2020) found that the factor that contributes to online cheating is the students' lack of knowledge or misunderstanding of their institution's academic integrity policy. Moreover, online examinations encourage the students to look for answers from their friends. Correspondingly, qualitative data of few CS pointed out instances of academic dishonesty in terms of assignment plagiarism, biases in grading and malpractices during online quiz and examinations (S9, S12, S13, S18, and S24). The research conducted by Holbeck et al. (2015,p.206) found, "Faculty stated that they reported plagiarism when students showed a blatant disregard of citing sources or when using information that was not their own, or submitting entire papers that were written by others". 
For the assessment of students' learning during online teaching, CA have mostly used quiz, discussion forum and assignment VLE features. The other online tools such as google forms, google classroom, pop-quiz, padlets and online cloud are also practiced by a few academics. Among these tools which are used for objective assessment are found to be giving timely feedback with real-time score which is consistent with study carried out by (Dorji et al., 2020) on "quiz in a virtual learning environment tool for assessing students' learning".

\section{Benefits and Challenges of using VLE features for online TLA}

The qualitative data analysis on the benefits of VLE features for online teaching are numerous. The majority of students voiced that the VLE platform provides a flexible learning environment despite the high cost of internet data. According to Yusnilita (2020,p.60), "It has various benefits over the traditional techniques of learning. A lot of the students are attracted because of its flexibility, although they need to pay for the cost to use the Internet". Similarly, the academics (L1, L3, L13, L19, and L21) indicated that they can upload teaching resources in any format which their students can access at any time and place. The discussion forum feature allows students to discuss on any topics of the subject. As stated by Bourne et al. (2019,p.24), “Online education will assist in writing (asynchronous systems) and speaking (synchronous systems)". Although a few students were not competent to participate actively in discussion forums, they sought help from friends. How to create anonymity of the students on VLE features which can be inclusive in nature during discussion forum? As Appanna(2008,p.9) reviewed the benefits and limitations of online learning in Fiji and found, "Another benefit of the online delivery method is that the associated anonymity can result in greater participation from all students, including shy ones. The lack of visual cues allows the instructor to treat all students in the same manner". L12 emphasized that the tutors can go through each of the discussion points that students have written and provide them feedback which may not be possible in normal classroom situations. The quiz feature is useful in conducting online tests. Only a few academics have reported that the VLE feature quiz is useful in evaluating students' learning outcomes. Interestingly, L18 said, "I could save my energy as well as time while assessing any MCQ assessments". Majority of the academics said that their students were able to upload assignments on VLE. The VLE assignment feature is more user friendly and easy to use by the students. These findings are consistent with the data analysed from the auto-generated report as shown in graph 1 .
Beside many benefits of using VLE features for online TLA, there are a few challenges faced by the academics and students. Only a handful academics are able to use advanced VLE features as illustrated in graph 1. Although in-house training or workshops on how to use VLE features for online TLA were conducted for academics by their colleges, still the majority of them are not competent to use advanced VLE features. The student respondent S20 voiced, "I just wish that all the tutors put an equal effort to teach us and provide us with the learning materials for the online session. Because I felt like some of the tutors take it easy". In contrast, some academics used other digital platforms (Facebook, WhatsApp, \&WeeChat) besides the VLE platform to interact and motivate students to participate in online teaching and learning. But the majority of students took time to adjust using different social media for online learning. As Mazlan et al. (2021,p.719) state:

During this pandemic outbreak, educators face difficulties in motivating students to participate and stay attentive during online learning. Aside from the difficulties to motivate, they also have difficulty interacting and supervising the students since they are not meeting them face-to-face.

Further, the students voiced that some of their tutors were not competent to teach online using VLE features. Most academics have just attempted to duplicate the real classroom situations by taking class through Zoom, Big Blue Button, and Google meet. So, there exists a diverse understanding of 'what online teaching and learning' really means. Theory based modules can be taught well through online but modules with practical components were difficult to teach without access to laboratory equipment, chemicals and apparatus. In order to make better learning experiences for students, there is still a need for academics to upscale their competency in using advanced VLE features. Several researchers reveal that online teaching is a complex task because it requires commitment from the academics and can be time consuming and demanding(Ahmed \&Ikram Khan, 2020;Azlan et al., 2020; Dhawan,2020).

The students have more challenging experiences of using VLE features. S35 said, "If we are taught to use every available feature in that platform it would be very easy for us to learn". Many researchers found that more training for teachers and students is essential for online TLA(Ahmed \&Ikram Khan, 2020; Gold, 2001; Lyndon \& Hale, 2014).The interaction of students, teachers and materials will be effective on the VLE platform, if the students are given enough training sessions on using VLE features. 


\section{CONCLUSION / RECOMMENDATIONS}

The three major findings on the perspectives of academics and students of the RUB regarding the effectiveness of the VLE for online TLA are: (a) The CA are more competent in using VLE features for online TLA than the CS. The factors that reinforced their competencies are availability of a stable network, timely in-house workshops, prior experiences of basic VLE features, and ICT knowledge. On the other hand, the majority of students faced problems while attending online classes. The factors that hinders them from active learning are unstable networks, erratic power supply, poor study environment, no financial support, and technical issues. However, the majority of students managed to overcome these challenges with the support from friends, tutors and relatives; (b) The benefits of using VLE features for online TLA by academics and students are learning to participate on VLE platform, improving their communication skills, enhancing their IT knowledge and skills, utilizing the time during lockdowns, and promoting social interactions; and (c)By using Mann-Whitney U test, it is found that there is no influence of gender, age, teaching experience, and educational qualification on the use of VLE features for online TLA.

The limitations of this research are: the topic of the study is broad; the sample size from all colleges is not uniform; and it is difficult to collect online quantitative and qualitative data. The future researchers can study by narrowing topic to specific and college-wise on the same topic or any of the following areas which are not covered in this study: (i) correlation between academic competency of delivering online TLA and students' performance in examinations;(ii) online strategies; and (iii) academic dishonesty.

Based on the findings of the study, the following recommendations are proposed.

- The online teaching was done more like a replication of face-to-face classroom sessions. It is pivotal to provide a series of trainings to academics on "how to design online instructions and interactive online educational resources.

- The advanced VLE features which are interactive and effective to engage the students' in learning were hardly used. So there is a need to provide professional development training to academics as well as to the students on advanced VLE features.

\section{AUTHOR CONTRIBUTIONS}

The authors have worked together and agreed to publish the manuscript.

\section{FUNDING}

This research was conducted with financial support (REF grant) from the Research Endowment Fund Governing Board, Office of Vice Chancellor, Royal University of Bhutan.

\section{ACKNOWLEDGMENTS}

The authors are immensely grateful to all research participants (academicians and students) of both constituent and affiliated colleges of Royal University of Bhutan for their active participation and honest responses. Without their unwavering support during such an unprecedented time of Covid-19 pandemic, this research paper would not have reached the present stage of 'on the verge of publication'. Our heartfelt gratitude goes to all ICT officers of 9 colleges for generously providing us auto-generated reports of VLE usage in different modules which became instrumental in triangulating our research findings. We also owe much to our close colleagues and students for tirelessly helping us in sharing online survey links, printing hardcopy questionnaires, collecting data and sending via posts and eventually contributing to our success.

\section{CONFLICTS OF INTEREST}

The authors declare no conflict of interest.

\section{REFERENCES}

[1] Adzima, K. (2020). Examining online cheating in higher education using traditional classroom cheating as a guide. Electronic Journal of E-Learning, 18(6), 476493.https://doi.org/10.34190/JEL.18.6.002

[2] Ahmed, A., \&Ikram Khan, A. (2020). Report on online teaching and learning amid COVID-19. National College of Business Administration \& Economics (NCBA\&E), Lahore, Pakistan. Available at SSRN 3646414. http://dx.doi.org/10.2139/ssrn.3646414

[3] Alves, P, Miranda, L. \&Morais, C. (2017). The influence of virtual learning environments in students' performance. Universal Journal of Educational Research,5(3), 517-527. https://doi.org/10.13189/ujer.2017.050325

[4] Appanna, S. (2008). Review of benefits and limitations of online learning in the context of the student, the instructor and the tenured faculty. International Journal on ELearning, 7(1), 5-22.https://eric.ed.gov/?id=EJ780471 
[5] Bolliger,D., \&Wasilik,O.(2009).Factors influencing faculty satisfaction with online teaching and learning in higher education. Distance Education, 30(1),103-116. https://doi.org/10.1080/01587910902845949

[6] Bourne, J., Harris, D., \&Mayadas, F. (2019). Online engineering education: Learning anywhere, anytime. Online Learning, 9(1). http://dx.doi.org/10.24059/olj.v9i1.1800

[7] Boylan, M. (2004). What have we learned from 15 years of supporting the development of innovative teaching technology?.Social Science Computer Review, 22(4), 405425.

https://www.researchgate.net/deref/http $\% 3 \mathrm{~A} \% 2 \mathrm{~F} \% 2 \mathrm{Fdx} . \mathrm{do}$ i.org\%2F10.1177\%2F0894439304268646

[8] Chandra, Y. (2020). Online education during COVID-19: Perception of academic stress and emotional intelligence coping strategies among college students. Asian Education and

Development Studies.https://www.emerald.com/insight/2046-3162.htm

[9] Chezom, S. \& Dem, K. (2020, March 6). Bhutan reports first COVID-19 case. Bhutan Broadcasting Service. http://www.bbs.bt/news/?p=129299

[10] Chua,C. \&Montalbo,J.(2014). Assessing students' satisfaction on the use of virtual learning environment (VLE): An input to a campus-wide e-learning design and implementation. Journal of Information \& Knowledge Management, 3(4),108-116. https://www.researchgate.net/publication/265599212_Asse ssing_Students'_Satisfaction_on_the_Use_of_Virtual_Lear ning_Environment_VLE_An_Input_to_a_Campus-wide_Elearning_Design_and_Implementation/citations

[11] Coman, C., Țîru, L.G., Meseșan-Schmitz, L., Stanciu, C.\&Bularca, M.C. (2020). Online teaching and learning in higher education during the coronavirus pandemic: Students' perspective. Sustainability 2020, 12(24), 10367. https://doi.org/10.3390/su122410367

[12] Crawford-Ferre, H, G. \& Wiest, L, R. (2012). Effective online instruction in higher education.The Quarterly Review of Distance Education,13(1),1-14. https://www.researchgate.net/publication/263620466_Effec tive_Online_Instruction_in_Higher_Education

[13] Creswell, J. W. (2014). Educational research: Planning, conducting and evaluating quantitative and qualitative research (4th ed.). PHI Learning Private Limited.

[14] Dhawan, S. (2020). Online learning: A panacea in the time of COVID-19 crisis. Journal of Educational Technology Systems, 49(1), 22.https://doi.org/10.1177/0047239520934018

[15] Dorji, C., Drukpa, P., \&Subba, B.H. (2020).Quiz in a virtual learning environment as a tool for assessing students' learning: Perception of Royal University of Bhutan lecturers. Education Innovation Practice, 4(2), 1223.

https://www.researchgate.net/publication/346625677_Quiz _in_a_Virtual_Learning_Environment_as_a_Tool_for_Ass essing_Students'_Learning_Perception_of_Royal_Universit y_of_Bhutan_Lecturers
[16] Gillett-Swan, J. (2017). The challenges of online learning: Supporting and engaging the isolated learner. Journal of Learning Design, 10(1), 2030.https://doi.org/10.5204/jld.v9i3.293

[17] Gold, S. (2001). A constructivist approach to online training for online teachers. Journal of Asynchronous Learning Networks, 5(1), 35-57. https://doi.org/10.24059/olj.v5i1.1886

[18] Hamutoglu, N.B., Gemikonakli, O., Duman, I., Kirksekiz, A., \&Kiyici, M.(2019). Evaluating students experiences using a virtual learning environment: Satisfaction and preferences. Education Tech Research Development. 68, 437-462. https://doi.org/10.1007/s11423-019-09705-z

[19] Herrera, L. (2017). Impact of implementing a virtual learning environment (VLE) in the EFL classroom. Ikala, 22(3),

479-

498.https://doi.org/10.17533/udea.ikala.v22n03a07

[20] Holbeck, R., Greenberger, S., Cooper, L., Steele, J., Palenque, S. M., \&Koukoudeas, S. (2015). Reporting plagiarism in the online classroom. Journal of online learning \& teaching, 11(2), 202-209. https://jolt.merlot.org/Vol11no2/Holbeck_0615.pdf

[21] Idowu, B., Ogunbodede, E., and Idowu, B. (2003). Information and communication technology in Nigeria: The health sector experience. Journal of Information Technology Impact, 3(2), 69-76. https://www.researchgate.net/publication/235248559_Infor mation_Communication_Technology_In_Nigeria_The_Hea 1th_Sector_Experience

[22] Jamtsho,S. \&Bullen,M. (2007). Distance education in Bhutan: Improving access and quality through ICT use. Distance Education, 28(2), 149-161. https://doi.org/10.1080/01587910701439217

[23] Kebritchi, M., Lipschuetz, A., \&Santiague, L. (2017). Issues and challenges for teaching successful online courses in higher education: A literature review. Journal of Educational Technology Systems, 46(1), 429.https://doi.org/10.1177\%2F0047239516661713

[24] Kinley, Zander, P.O., Georgsen, M., \&Choeda.(2013). The usage of ICT for teaching at a bhutanese college. https://www.researchgate.net/publication/264315632_The_ Usage_of_ICT_for_Teaching_at_a_Bhutanese_College

[25] Koi-Akrofi, G. Y., Owusu-Oware, E., \&Tanye, H. (2020). Challenges of distance, blended, and online learning: A literature-based approach. International Journal on Integrating Technology in Education, 9(4), 17-39.

[26] Li, L.Y., Lee, L.Y. (2016). Computer literacy and online learning attitude toward GSOE students in distance education programs. Higher Education Studies,6(3), 19254741.https://doi.org/10.5539/hes.v6n3p147

[27] Lopes,A.P.(n.d). Teaching with moodle in higher education.

https://pdfs.semanticscholar.org/c23f/70b72eccb46b157025 8bb3fff345b6885ea8.pdf

[28] Love, N. \& Fry, N. (2006). Accounting students' perceptions of a virtual learning environment: Springboard or safety net?.Accounting Education: An International Journal, $\quad 15 \quad$ (2), 151-166. 
https://www.tandfonline.com/doi/abs/10.1080/0693928060 0609201

[29] Lyndon, S., \& Hale, B. (2014). Evaluation of how the blended use of a virtual learning environment (VLE) can impact on learning and teaching in a specific module. Enhancing Learning in the Social Sciences, 6(1), 56-65.https://doi.org/10.11120/elss.2014.00019

[30] Maltby, A., \& Mackie, S. (2009). Virtual learning environments - help or hindrance for the 'disengaged' student?.Research in Learning Technology, 17(1). https://doi.org/10.3402/rlt.v17i1.10863

[31] Mazlan, A., Mohamad, M., Reesha, A., Kassim, R., Othman, Z. and Kummin, S. (2021). Challenges and strategies to enhance online remote teaching and learning by tertiary institution educators: A literature review. Creative Education, 12, 718-726. doi: 10.4236/ce.2021.124050.

[32] Ministry of Education. (2019). iSherig-2 education ICT master plan 2019-2023. Ministry of Education, Royal Government of Bhutan. http://www.education.gov.bt/wpcontent/uploads/2019/05/iSherig-2-Education-ICTMNasterplan-2019-2023.pdf

[33] Ministry of Education. (2019). iSherig-2 education ICT master plan 2019-2023. Ministry of Education.

[34] Ministry of Education.(2014).Bhutan education blueprint 2014-2024- Rethinking education. Ministry of Education. http://www.education.gov.bt/wp-

content/downloads/publications/publication/Bhutan-

Education-Blueprint-2014-2024.pdf

[35] Molotsi, A. R. (2020). The university staff experience of using a virtual learning environment as a platform for elearning. Journal of Educational Technology \& Online learning, 3(2), 133-151. https://www.researchgate.net/publication/340879901_The_ university_staff_experience_of_using_a_virtual_learning_e nvironment_as_a_platform_for_e-learning

[36] Nguyen, T. (2015). The effectiveness of online learning: Beyond no significant difference and future horizons. MERLOT Journal of Online Learning and Teaching, 11(2), 309-319.Microsoft Word - 12 Nguyen .docx (researchgate.net)

[37] Olsen, H. (2007). Considerations for delivery of online professional development for childcare professionals.[ Doctoral dissertation, University of Northern Iowa]. Dissertations and Theses @ UNI. 350. https://scholarworks.uni.edu/etd/350

[38] Paudel, P. (2021). Online education: Benefits, challenges and strategies during and after COVID-19 in higher education. International Journal on Studies in Education, 3(2), 70-85.https://doi.org/10.46328/ijonse.32

[39] Sadeghi, M. (2019). A shift from classroom to distance learning: Advantages and limitations. International Journal of Research in English Education, 4(1), 8088.ijreeonline.com/article-1-132-en.pdf

[40] Singh, V. \& Thurman, A. (2019). How many ways can we define online learning? A systematic literature review of definitions of online learning (1988-2018). American
Journal of Distance Education, 33(4), 289-306. https://doi.org/10.1080/08923647.2019.1663082

[41] Stodel, E. J., Thompson, T. L., \& MacDonald, C. J. (2006). Learners' perspectives on what is missing from online learning: Interpretations through the community of inquiry framework. The International Review of Research in Open and Distributed Learning, 7(3). https://doi.org/10.19173/irrodl.v7i3.325

[42] Tom.(2017,Nov 29).The history of online education.https://www.petersons.com/blog/the-history-ofonline-education/

[43] Wood, B. E. (2019). 21st century learners: Changing conceptions of knowledge, learning and the child. New Zealand Annual Review of Education, 23, 20-35. https://doi.org/10.26686/nzaroe.v23i0.5280

[44] Yusnilita, N. (2020). The impact of online learning: Student's views. ETERNAL (English Teaching Journal), 11(1). https://doi.org/10.26877/eternal.v11i1.6069

[45] Yusuf, M.O., \& Yusuf, H.T. (2009). Education reform in Nigeria: The potentials of information and communication technology. Education Research and Review, 4(5), 225230. https://academicjournals.org/journal/ERR/article-fulltext-pdf/4C628734078 